\title{
Bridging the Gap between EPMA and AEM: The Performance of High Resolution Field-Emission Electron Microprobes in the Analysis of Geological Materials
}

\author{
John T. Armstrong ${ }^{1}$, Peter McSwiggen ${ }^{2}$ and Charles Nielsen ${ }^{3}$ \\ 1. Geophysical Laboratory, Carnegie Institution of Washington, Washington, DC, USA. \\ 2. McSwiggen and Associates, P.A., St. Anthony, MN, USA. \\ 3. JEOL USA, Peabody, MA, USA.
}

The use of quantitative electron microprobe analysis has revolutionized the two-dimensional elemental characterization of Earth materials at the micro-scale. The newly available commercial field emission (FE-) source instruments represent significant technological advances in quantitative measurement with high spatial resolution at sub-micron scale - helping to bridge the gap between conventional microprobe and AEM analyses. Their performance specifications suggest the ability to extend routine quantitative analyses from $\sim 3-5 \mu \mathrm{m}$ diameter areas down to $1-2 \mu \mathrm{m}$ diameter at beam energies of $15 \mathrm{keV}$; and, with care, down to 200-500 $\mathrm{nm}$ diameter at reduced beam energies. Early published data obtained from use of these instruments suggest that exciting new capabilities are opening up (e.g., [1]).

In order to determine whether the level of performance suggested by the specifications is realistic, we spent four days doing analyses at the newly installed JEOL JXA-8530F field emission microprobe at Arizona State University, using a series of samples that are currently being studied in various projects at CIW. These tests confirmed that significantly improved analytical performance can be achieved using integrated WDS and SDD-EDS measurements - including quantitative x-ray imaging down to $200 \mathrm{~nm}$ resolution, quantitative $\mathrm{x}$-ray line scans at a resolution of $<300 \mathrm{~nm}$, and accurate quantitative analysis of $<400 \mathrm{~nm}$ diameter grains, all performed at beam energies of $7 \mathrm{keV}$ and currents of $20 \mathrm{nA}$.

Figures 1-3 show typical results obtained. X-ray line profiles across high- and low-Ni Fe-alloys in a pallasite meteorite show linear concentration variation within $1 \mu \mathrm{m}$ of their contacts (Fig. 1b) not visible using a conventional microprobe (Fig. 1c; also [2a]). This gradient, which has been confirmed by AEM measurements at much lower precision can be used to determine the meteorite's cooling rate (e.g, [2b]). Figure 2 shows a fine-grained intergrowth of sub- $\mu \mathrm{m}$ phases in a section of a flood basalt from Siberia. Laths as thin as $100 \mathrm{~nm}$ can be seen in the map; and we were able to analyze phases as small as $300 \mathrm{~nm}$ without significant contribution from their surroundings. Such determinations are critical in determining the T, P and fluid compositions involved in their formation. Figure 3 show a typical analysis of a sub$\mu \mathrm{m}$ pyroxene grain we were able to obtain in a very fine-grained intergrowth of crystals and glass in a chondritic meteorite. Previous papers on this meteorite stated that this sample was too fine grained to be analyzed with the electron microprobe. The results of these and many other analyses we obtained suggest that field emission electron microprobes can reduce the attainable analytical areas by close to an order of magnitude opening up a broad new range of applications in the earth sciences.

\section{References:}

[1] J. J. Ague and J. O. Eckert, Am. Mineral. 87, (2012) p. 840.

[2] J. Yang et al., Geochim. Cosmochim. Acta 74, (2010) (a) p. 4471; (b) p. 4471.

[3] The authors thank the Leroy Eyring Center for Solid State Science at Arizona State University for making their new field emission electron microprobe available to us for this study. 

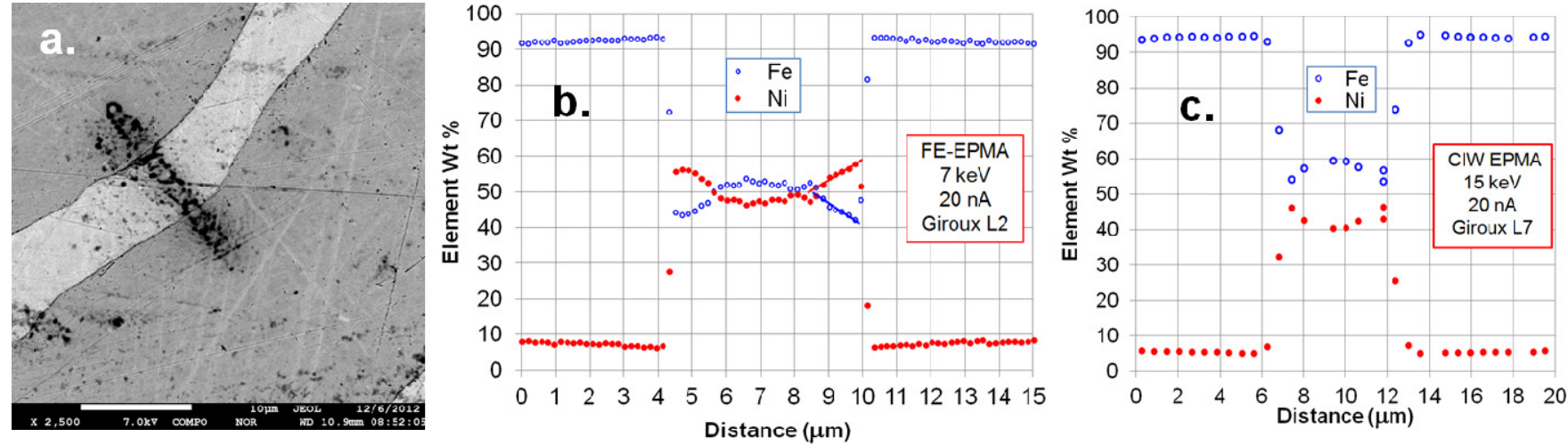

Figure 1. (a) BE image (scale bar $10 \mu \mathrm{m}$ ) and WDS x-ray line profiles of Fe L $\alpha$ and Ni L $\alpha$ across kamacite-taenite boundaries in the Giroux pallasite with (b) FE- and (c) W-source electron microprobes.

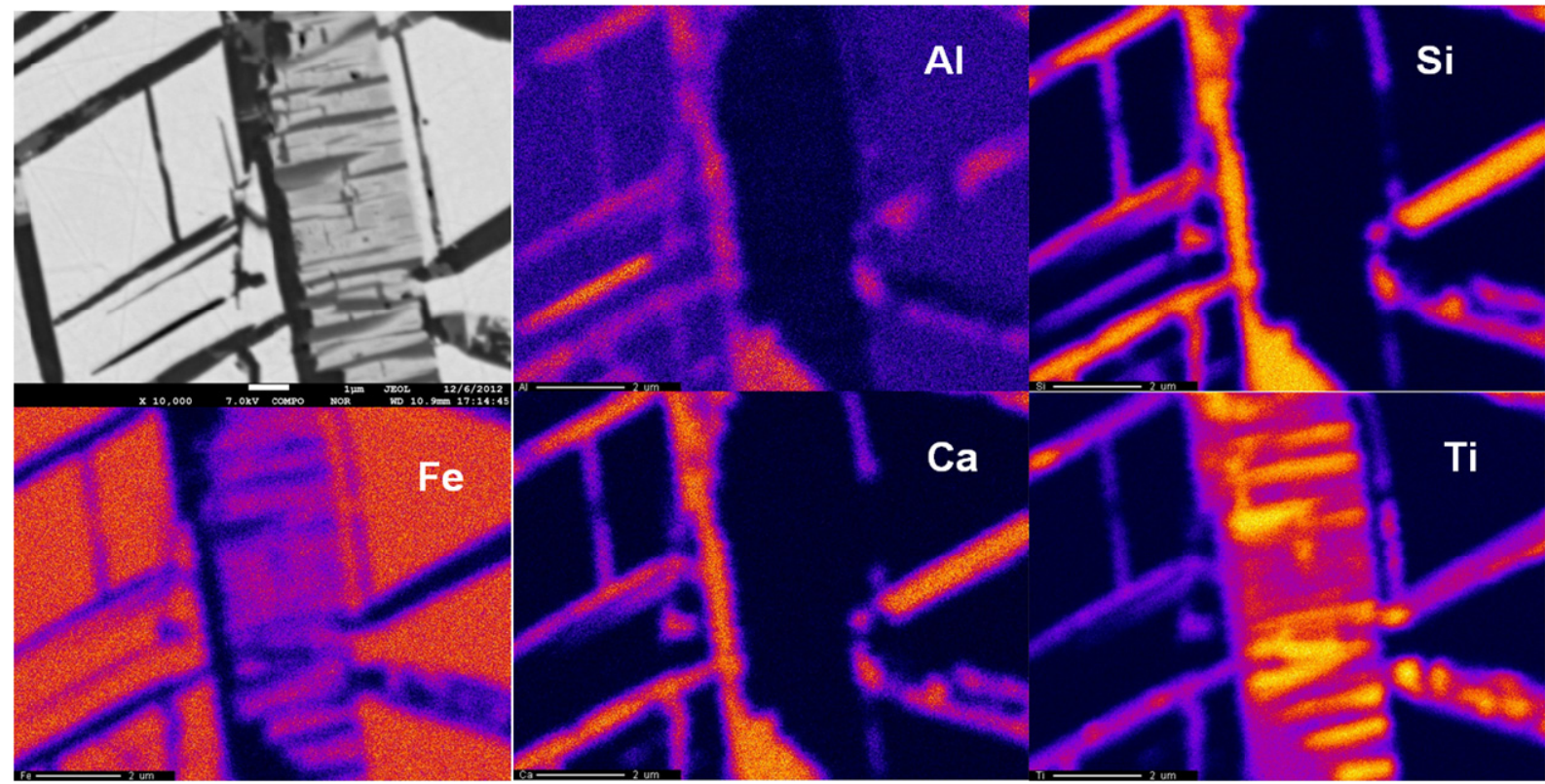

Figure 2. BE image and WDS x-ray maps of a sub- $\mu$ m intergrowth of rutile $\left(\mathrm{TiO}_{2}\right)$, titanite $\left(\mathrm{CaTiSiO}_{5}\right)$, and Al-rich magnetite $\left(\mathrm{Fe}_{3} \mathrm{O}_{4}\right)$ in a section of Ivakinsky basaltic rock, Siberia. Maps are $12 \mu \mathrm{m}$ x $9 \mu \mathrm{m}$.

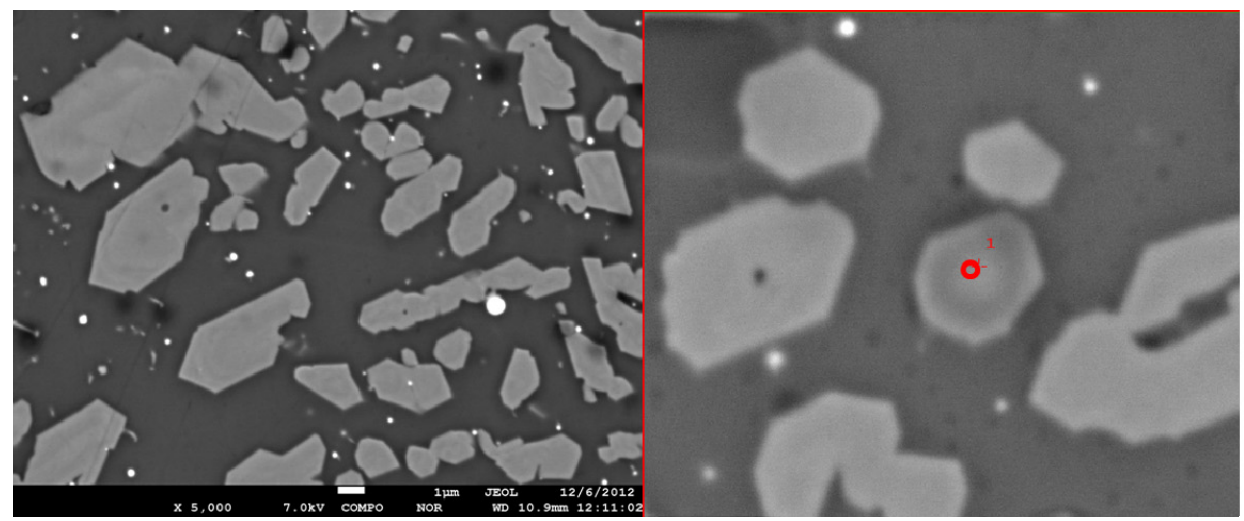

\begin{tabular}{ccc} 
Element & El. Wt\% & At prop. \\
Mg & 8.29 & 3.10 \\
$\mathrm{Ca}$ & 12.74 & 2.89 \\
$\mathrm{Fe}$ & 10.57 & 1.72 \\
$\mathrm{Ni}$ & 0.05 & 0.01 \\
$\mathrm{Na}$ & 0.66 & 0.26 \\
"A" & & 7.98 \\
$\mathrm{Al}$ & 0.71 & 0.24 \\
$\mathrm{Cr}$ & 1.65 & 0.29 \\
$\mathrm{Si}$ & 23.61 & 7.65 \\
$\mathrm{Ti}$ & 0.11 & 0.02 \\
"B" & \multicolumn{3}{c}{8.20} \\
O & 42.18 & 24.00 \\
------------------- \\
Total: & 100.58 &
\end{tabular}

Figure 3. Analysis of $700 \mathrm{~nm}$ pyroxene grain in contact with K-Al-rich glass in Semarkona chondrule, showing no analytical overlap with the surrounding glass and consistent with larger pyroxene grains. 